\title{
PENGARUH BUDAYA ORGANISASI DAN MANAJEMEN PENGETAHUAN TERHADAP KEUNGGULAN BERSAING
}

\author{
Dian Indiyati \\ Departement of Management, Faculty of Economics, University of Jenderal Ahmad Yani Cimahi \\ E-mail : dianinds@yahoo.com
}

\begin{abstract}
Abstrak Persaingan yang sangat ketat pada bidang pendidikan, menuntut setiap Perguruan Tinggi Swasta (PTS) untuk mempunyai keunggulan bersaing. PTS harus memberikan perhatian yang lebih serius pada manajemen pengetahuan dan budaya organisasi. Dengan adanya manajemen pengetahuan, PTS dapat menyimpan, meng-update dan menyempurnakan terus menerus secara detail tentang pengetahuan praktis dari semua lapisan profesional dan pekerja. Melalui manajemen pengetahuan, dengan didukung adanya penerapan budaya organisasi yang kuat, para pemimpin, dosen dan staf pada PTS tidak hanya berbagi pengalaman dan pengetahuan, tetapi anggota organisasi PTS akan selalu menularkan cara berpikir kepada orang lain dengan ide-ide nya sehingga menjadi lebih kreatif dan inovatif.Tujuan dari penelitian ini adalah untuk mengkaji dan menganalisis pengaruh budaya organisasi dan manajemen pengetahuan, baik secara simultan maupun parsial terhadap keunggulan bersaing pada PTS Kopertis Wilayah IV. Metode penelitian yang digunakan pada penelitian ini yaitu explanatory survey. Unit Analisis pada penelitian ini adalah organisasi, populasinya adalah PTS Kopertis Wilayah IV, dan sampel yang digunakan adalah probability sampling, yang berjumlah 157 PTS. Pengumpulan datanya dilakukan dengan menggunakan teknik observasi, wawancara dan kuesioner yang telah diuji validitas dan reliabilitasnya. Analisis data yang digunakan adalah Structural Equation Modeling (SEM) dengan pendekatan second order. Hasil penelitian menyimpulkan bahwa budaya organisasi dan manajemen pengetahuan berpengaruh secara simultan terhadap keunggulan bersaing pada PTS Kopertis Wilayah IV, kemudian secara parsial, budaya organisasi memberikan pengaruh positif terhadap keunggulan bersaing, sedangkan manajemen pengetahuan, tidak mempunyai pengaruh signifikan terhadap keunggulan bersaing pada PTS Kopertis Wilayah IV.
\end{abstract}

Kata Kunci : Budaya Organisasi, Manajemen Pengetahuan, Keunggulan Bersaing

\section{AN INFLUENCE OF ORGANIZATIONAL CULTURE AND KNOWLEDGE MANAGEMENT TOWARD THE COMPETITIVE ADVANTAGE}

\begin{abstract}
The tight competition in education sector led to the private university provides the superior competitiveness. By knowledge management, private colleges can improving continuously in detail on knowledge by all professional level and staff. By knowledge management sustained in implementation of powerful organization culture, leader, lecturer and staff of private college do not only share the experience and knowled, but also the member of university will pass on the mainset to the other by their ideas to be creative and innovative.The study intends to review and analyzing an organization culture and knowledge management impact simultan or partially toward the competitiveness of private colleges in Kopertis Region IV.A method used in research is explanatory survey, the population is private colleges of Kopertis Region IV, and sample used is probability sampling, total 157 private colleges. Data collection technique used is observation, interview and reliable questionnaire in validity. Data analysis is Structural Equation Modeling (second order method) The result is, in simultan, organizational culture and knowledge management has influence to the competitive advantage of private colleges in Kopertis Region IV, in partial, the organizational culture has influences to the competitive adavantage, however knowledge management do not influence significantly to the competitive advantage.
\end{abstract}

Keywords : organizational culture, knowledge management, competitive advantage

\section{PENDAHULUAN}

Perkembangan perguruan tinggi Indonesia dalam persaingan internasional dikatakan masih belum maksimal, hal ini terlihat pada perangkingan perguruan tinggi se dunia yang dipaparkan oleh webometrics (2010), yaitu perguruan tinggi negeri (PTN) berada pada rangking di atas 500, perguruan tinggi swasta (PTS) berada pada peringkat di atas 800 , sedangkan PTS Kopertis Wilayah IV berada pada peringkat di atas 3000 (Indiyati, 2012).

Fenomena berikutnya yang terjadi bahwa sebanyak $30 \%$ atau sekitar 800 -an PTS di Indonesia gulung tikar, karena tidak mampu bersaing dengan perguruan tinggi lainnya, termasuk dengan PTN (Kompas.com , 2008), hal ini karena PTS tersebut tidak bisa berkreasi dan berinovasi, PTS tersebut tidak mampu beradaptasi dengan kebutuhan masyarakat, padahal untuk dapat bersaing sangat dibutuhkan kreativitas dan inovatifyang tinggi, antara lain mengkreasi kurikulum sedemikian rupa yang disesuaikan dengan kebutuhan pengguna lulusan, sehingga dapat menghasilkan lulusan yang dibutuhkan oleh pengguna lulusan. (Wayah, 2008). Bahkan Akhmadi (2008) menambahkan bahwa dalam bersaing, PTS juga harus mampu membangun pusatpusat unggulan di kampusnya.

Salah satu kendala dalam mengembangkan perguruan tinggi swasta antara lain PTS belum mempunyai karakteristik yang dapat dijadikan sebagai penciri khusus, yaitu masih belum kuatnya budaya organisasi yang diluhurkan dan ditumbuhkan dalam PTS (Setiawan : 2010). Selanjutnya berdasarkan data yang disajikan oleh Kopertis Wilayah IV pada tahun 2009, 
dinyatakan bahwa Angka Partisipasi Kasar (APK) di Jawa Barat yaitu 7,4\%, secara nasional yaitu $17,4 \%$, berarti masih agak rendah. Hal ini menandakan bahwa masih banyak siswa lulusan SMA sederajad, yang belum kuliah pada perguruan tinggi. Hal ini diduga karena beberapa PTS Kopertis Wilayah IV belum maksimal dalam membidik calon mahasiswanya, berarti PTS melakukan kegiatan promosinya belum maksimal, sehingga perolehan jumlah mahasiswa barunya juga belum maksimal. Promosi yang dilakukan oleh PTS dengan tidak gencar tersebut, dapat disebabkan karena PTS diduga tidak cukup berani untuk mengambil risiko dalam biaya promosinya (Indiyati:2012).

Kurang tertibnya administrasi, antara lain EPSBED, juga menjadi permasalahan pada PTS Kopertis Wilayah IV. Realitanya, masih banyak terjadi program studi terlambat dalam memperpanjang ijin pendiriannya. Hal ini terjadi, diduga karena kurang maksimalnya pengawasan atau pengendalian dari pimpinan PTS, karena belum maksimalnya ketersediaan sistem informasi atau belum efektifnya sistem informasi, begitu pula belum maksimalnya dalam proses penyimpanan data pada PTS yang bersangkutan (Indiyati : 2012).

Berdasarkan wawancara peneliti dengan beberapa pimpinan PTS (2010), bahwa pertemuan formal yang secara rutin dijalankan, hanya berupa rapat pimpinan, sedangkan pertemuan formal dosen yang membahas tentang hasil riset dosen, tulisan ilmiah dosen, belum maksimal dijalankan, hal ini menandakan kegiatan knowledge sharing belum menjadi hal yang penting untuk dijalankan di lingkungan organisasi perguruan tinggi tersebut.

Berdasarkan beberapa permasalahan yang diuraikan, maka menjadi suatu hal yang menarik untuk dikaji dan dianalisis dalam bentuk penelitian tentang pengaruh budaya organisasi dan manajemen pengetahuan terhadap keunggulan bersaing. Permasalahan pada penelitian ini difokuskan pada Perguruan Tinggi Swasta (PTS) Kopertis Wilayah IV. Tujuan dari penelitian/penulisan ini yaitu untuk mengkaji dan menganalisis pengaruh budaya organisasi dan manajemen pengetahuan terhadap keunggulan bersaing pada PTS Kopertis Wilayah IV baik secara simultan maupun secara parsial.

\section{Budaya Organisasi}

Robbins (2008) mengungkapkan tentang budaya organisasi sebagai sebuah persepsi umum yang dipegang oleh anggota organisasi, suatu sistem tentang keberartian bersama. Budaya organisasi berkepentingan dengan bagaimana pekerja merasakan karakteristik suatu budaya organisasi, tidak dengan apakah seperti mereka atau tidak. Sedangkan menurut Kreitner dan Angelo Kinicki (2008), budaya organisasi adalah nilainilai dan keyakinan bersama yang mendasari identitas perusahaan. Want (2006) memberikan pengertian budaya organisasi sebagai sebuah sistem keyakinan kolektif yang dimiliki orang dalam organisasi tentang kemampuan mereka bersaing di pasar, dan bagaimana mereka bertindak dalam sistem keyakinan tersebut untuk memberikan nilai tambah produk dan jasa di pasar (pelanggan) sebagai imbalan atas penghargaan finansial. Budaya organisasi diungkapkan melalui sikap, sistem, keyakinan, impian, perilaku, nilai-nilai, tatacara dari perusahaan dan terutama melalui tindakan serta kinerja pekerja dan manajemen.

Berarti Budaya Organisasi merupakan sesuatu hal yang sifatnya mendasar, yang berisi keyakinan, nilai-nilai inti bersama, sesuatu yang menjadi karakteristik inti, yang diyakini dan dijalankan bersama-sama oleh semua anggota organisasi. Budaya organisasi mencerminkan persepsi umum yang dilakukan oleh seluruh anggota organisasi.

Budaya organisasi dalam suatu organisasi yang satu dengan organisasi yang lain, dapat berbeda, karena budaya organisasi dapat menunjukkan ciri-ciri, sifat atau karakteristik tertentu. Berikut ini diuraikan tentang karakteristik budaya organisasi, menurut pendapat dari Gordon dan Cummins (dalam Robbins, 2008) serta Tan (2002), yaitu :

a. Individual initiative : adanya ketidaktergantungan atau kebebasan yang dimiliki individu untuk berkreasi dan berinovasi, dengan tetap bertanggung jawab. Kreasi merupakan kemampuan berpikir sesuatu yang baru, sedangkan inovasi merupakan kemampuan untuk bertindak yang baru (Zimmerer, 1996 dan Levitt, 1997). Selanjutnya, yang dimaksud dengan bertanggung jawab adalah mengerjakan pekerjaannya sesuai dengan job description nya (Mondy\&Noe, 2006).

b. Risk tolerance : keadaan dimana pegawai berani untuk mengambil risiko, agar menjadi agresif dan inovatif.

c. Direction : kemampuan organisasi menciptakan sasaran yang jelas dan menetapkan harapan kinerja. Agar penetapan sasaran organisasi lebih jelas dan lebih terarah, maka sebaiknya sasaran tersebut dapat diukur, dihitung, dan jelas ukuran waktunya, ditulis berdasarkan hasil bukannya tindakan, tertulis serta dikomunikasikan kepada anggota organisasi yang terkait, kemudian sasaran tersebut ditetapkan secara bersama-sama oleh para pegawai terkait dan para manajer, tidak hanya ditetapkan oleh pimpinan tingkat atas saja (Robbins, 2008).

d. Integration : tingkatan dimana suatu unit dalam organisasi bekerja bersama-sama dengan cara terkoordinasi.

e. Management support : manajer menyediakan bantuan dan dukungan kepada bawahannya

f. Control: merupakan jumlah aturan dan ketentuan, serta pengawasan langsung dari pimpinan, yang dipergunakan untuk melihat dan mengawasi perilaku karyawan. Peraturan yang lengkap adalah peraturan yang dibuat dengan mengarah pada pola pembinaan disiplin, yang memuat peraturan (kewajiban dan larangan), sanksi dan pelatihan (Rivai, 2004). Sedangkan pengawasan langsung dari pimpinan yang efektif, dilakukan secara rutin dengan melakukan monitoring dan evaluasi (Bateman et al., 2007) 
g. Identity : tingkatan dimana anggota bangga menjadi bagian organisasi secara keseluruhan, dibandingkan dengan kelompok kerja tertentu atau bidang keahlian profesional tertentu, serta adanya pengenalan dari pihak eksternal .

h. Reward system : reward diberikan berdasarkan pada kriteria kinerja, sebagai lawan dari senioritas dan favoritisme. Pemberian balas jasa sebaiknya memenuhi prinsip konsistensi, baik internal maupun eksternal. Konsistensi internal berarti memenuhi keadilan internal, yang didasarkan pada nilai relatif suatu jabatan, sedangkan kelayakan berarti disesuaikan dengan kemampuan perusahaan dan peraturan pemerintah (Cascio, 2003; Ruky, 2002; Werther\&Davis, 1996)

i. Conflict Tolerance : suatu keadaan dimana penyelesaian konflik diselesaikan dengan sering menerima saran, kritikan, dan bersifat terbuka.

j. Communication pattern : tingkatan dimana komunikasi dibatasi pada kewenangan hirarki formal. Agar permasalahan organisasi dapat diselesaikan lebih efektif, dan untuk menghindari permasalahan organisasi agar tidak menjadi lebih meluas, maka sebaiknya dibatasi aliran komunikasinya (Sopiah, 2008).

\section{Manajemen Pengetahuan}

Manajemen pengetahuan merupakan sistem yang dibuat untuk menciptakan, mendokumentasikan, menggolongkan, dan menyebarkan pengetahuan dalam organisasi. Sehingga, pengetahuan mudah digunakan kapan pun diperlukan, oleh siapa saja sesuai dengan tingkat otoritas dan kompetesinya. (Widayana, 2005). Selanjutnya, Zhou\&Dieter Fink (2003) mengatakan bahwa manajemen pengetahuan adalah mengelola proses organisasi untuk membuat, menyimpan dan menggunakan kembali pengetahuan organisasi.

Berarti, manajemen pengetahuan merupakan suatu proses manajemen yang berbasiskan pengetahuan, yang tujuannya adalah bagaimana menciptakan sarana dan lingkungan yang mendukung terhadap proses penciptaan, penyebaran, aplikasi dan perlindungan pengetahuan di dalam suatu organisasi. Manajemen pengetahuan merupakan upaya sistematis untuk mendorong dan memfasilitasi aliran pengetahuan antar elemen di dalam suatu organisasi sehingga dapat mempercepat proses pembelajaran organisasi.

Hsu (2006) dan Nguyen, et al (2009) menyatakan bahwa dalam perusahaan menjalankan proses manajemen pengetahuan terdapat empat hal yang harus diperhatikan, yaitu : knowledge acquisition (mengumpulkan pengetahuan, mencari pengetahuan baru dan membuat yang baru pengetahuan dari pengetahuan yang ada/mendesain ulang pengetahuan); knowledge conversion (kemampuan untuk mendeteksi pengetahuan agar menjadi lebih berguna); knowledge application (melakukan penyimpanan yang efektif dan pengambilannya, dan memungkinkan organisasi untuk cepat me ngakses pengetahuan yang disimpan); knowledge protection (dirancang untuk melindungi pengetahuan dalam suatu organisasi dari ilegal atau pencurian). Pendapat lain dikemukakan oleh Dalkir (2005), terdapat 3 unsur pelaksanaan manajemen pengetahuan, yaitu :

a. Knowledge Creation.

Penciptaan pengetahuan dapat difasilitasi melalui desain pekerjaan, antara lain dengan memberikan tugas-tugas kepada tim-tim kerja, bukan kepada individu (Moharman, 2003; Nonaka\&Takeuchi, 1995). Menurut Hsu (2006), knowledge creation dapat dilakukan dengan menciptakan produk baru dan layanan baru, dapat pula menciptakan prosedur baru, proses baru, pekerjaan baru, sistem baru dan peraturan-peraturan baru, bahkan pendapat Birkinsaw (2002), dalam penerapan knowledge creation, tidak hanya menciptakan pengetahuan baru, tapi juga mendaur ulang, seperti memperbaiki proses.

b. Knowledge Transfer / Knowledge Sharing, Untuk bersaing secara efektif dalam ekonomi berbasis pengetahuan, memperoleh atau menciptakan pengetahuan itu penting bagi organisasi, tetapi proses-proses tersebut tidak dapat mencapai hasil yang optimal, jika pengetahuan tersebut tidak disebarkan (shared). Knowledge transfer is the process through which an individual, team, departement or division is affected by the experience of an other (Argote, et al., dalam Noe et al., 2003).

Tahapan dalam proses knowledge sharing terdiri dari : Socialization, Externalization, Combination dan Internalization/SECI, dimana SECI merupakan continuous process, yang dapat mendorong penciptaan pengetahuan melalui interaksi secara vertikal dan horizontal, melalui pertukaran antar individu, antar bagian, antar departemen dan bahkan antar organisasi. (Nonaka, 2007 dan Noe, 2003)

1). Socialization : merupakan sharing tacit knowledge antar individu. Sharing dapat dilakukan melalui direct experience seperti menghabiskan waktu bersama dalam menyelesaikan pekerjaan, magang, day to day social interaction, coaching atau mengikuti suatu pelatihan untuk mengamati bagaimana seorang tenaga ahli menyelesaikan pekerjaannya, dapat dilakukan dengan cara pertemuan formal dan informal untuk saling bertukar gagasan, pengalaman dan keahlian karyawan.

2). Externalization : merupakan proses mengartikulasikan tacit knowledge dengan menggunakan bahasa simbolik, menterjemahkan tacit knowledge ke dalam konsep atau prototype dan selanjutnya didokumentasikan untuk disebarkan. Externalization merupakan proses menkonversikan tacit knowledge menjadi explicit knowledge, melalui proses pendokumentasian, seperti menuangkan ide dan atau keahlian SDM ke dalam bentuk tulisan (Pariokh et al., dalam Aulawi, 2009)

3). Combination : konversi atau integrasi dari explicit knowledge tadi dengan explicit knowledge lain dari praktik terpadu atau terkait dalam perusahaan. New knowledge yang siap pakai disebarkan diantara warga dari organisasi. Combination 
merupakan pertukaran explicit knowledge melalui sharing dokumen, prosedur atau kebijakan.

4). Internalization : dilakukan melalui penerapan dan penggunaan explicit knowledge ke dalam praktical situations, yang bertujuan agar explicit knowledge dapat dipahami secara praktis, hal ini merupakan proses implementasi explicit knowledge yang dilakukan karyawan secara bersama-sama. Dalam internalization, mengubah explicit knowledge menjadi tacit knowledge dapat dilakukan melalui simulasi, pembelajaran tindakan dan pengalaman di tempat kerja. Menurut Noe (2003), sebagian besar pengetahuan baik tacit maupun explicit, disebarkan melalui pengalaman kerja dan hubungan rekan kerja sejawat, pelanggan, manajer dan mentor, saat pernyataan diajukan dan saat pengalaman, cerita atau narasi disebarkan.

c. Knowledge Utilization

Menurut Saito dan Umemoto (dalam Syaiful, 2007), knowledge utilization dapat diartikan juga sebagai knowledge application, dapat berupa document management, groupware dan E-Learning.

Berdasarkan uraian tersebut maka dapat dinyatakan bahwa secara garis besar proses manajemen pengetahuan terdiri atas proses penciptaan, penyebaran, penyimpanan dan penerapan, serta perlindungan pengetahuan.

\section{Keunggulan Bersaing}

Dessler (2007) mengemukakan bahwa "Competitive Advantage is any factor that allow an organization to differentiate its products or service from those of its competitor to increase market share". Menurut Noe et al (2010), competitive advantage is a company's ability to make product or offer services that are valued by customer more than those of competing firms. Selanjutnya, Hsu (2006), menyatakan bahwa "Competitive Advantage is initiated when a product can be delivered with a sufficient value at a lower cost than other competitors can in marketplace".

Jadi, dapat dinyatakan bahwa keunggulan bersaing merupakan strategi perusahaan yang dirancang untuk menciptakan sesuatu yang baru dan berbeda, yang tidak dapat ditiru oleh pesaing, dihargai dengan nilai lebih dan dapat diterima oleh pasar, untuk mencapai peluang-peluang yang menguntungkan, yang dapat dilakukan melalui strategi inovasi, kualitas dan strategi biaya.

Strategi kompetitif yang dapat digunakan oleh organisasi untuk memperoleh keunggulan kompetitif, dikemukakan oleh Porter (dalam Schuller\&Susan E Jackson, 2006), yaitu :

a. Strategi Inovasi

Liao et al (2007), menyatakan bahwa inovasi seringkali dijelaskan sebagai perubahan yang ditawarkan perusahaan kepada khalayak luas (product/service innovation) serta cara menciptakan dan menyampaikan perubahan (process innovation). Selanjutnya, diungkapkan bahwa kemampuan inovasi perusahaan mencakup product/service innovation, yaitu kemampuan perusahaan untuk menawarkan diferensiasi produk atau jasa baru ke dalam suatu pasar dan memperoleh kepuasan pelanggan; kemudian process innovation, yaitu kemampuan perusahaan untuk menghasilkan suatu proses manufaktur atau jasa yang lebih baik dibandingkan dengan proses yang ada saat ini, atau kemampuan perusahaan untuk selalu melakukan modifikasi atau penciptaan proses baru terhadap tahapan operasional/ prosedur yang ada saat ini; berikutnya management innovation, merupakan kemampuan perusahaan untuk meningkatkan performansinya melalui implementasi peraturan, sistem dan metoda manajerial yang baru.

b. Strategi Kualitas Pelayanan

Kualitas pada penelitian ini lebih difokuskan pada kualitas pelayanan, karena obyek penelitiannya adalah perguruan tinggi, yang bergerak di bidang jasa. Kualitas pelayanan, mengacu pada konsep yang diutarakan oleh Kotler (2010), yaitu Tangible, Empati, Reliability, Responsive dan Assurance. Tangible merupakan tampilan fisik, dapat berupa fasilitas fisik, perlengkapan. Empati yaitu perhatian dan memahami kebutuhan pelanggan. Reliability adalah kemampuan memberikan pelayanan dengan segera, akurat dan memuaskan. Responsive, yakni memberikan pelayanan dengan tanggap atau cepat dalam merespon. Selanjutnya Assurance merupakan sifat dapat dipercaya atau memberikan adanya kepastian

c. Strategi Biaya.

Karakteristik dari suatu perusahaan yang menjalankan strategi biaya adalah adanya kontrol-kontrol yang ketat, prinsip minimalisasi overhead dan pencapaian skala ekonomi.

Berdasarkan beberapa konsep yang sudah diuraikan, dapat dinyatakan hipotesis pada penelitian ini, yaitu budaya organisasi dan manajemen pengetahuan berpengaruh terhadap keunggulan bersaing pada PTS Kopertis Wilayah IV, baik secara simultan maupun secara parsial.

\section{METODE}

Metode penelitian yang digunakan adalah explanatory survey method, dimana berdasarkan pada tipe penyelidikannya yaitu causal relationship, berdasarkan pada sifat penelitiannya yaitu penelitian verifikatif. Unit analisis pada penelitian ini adalah organisasi PTS Kopertis Wilayah IV. Populasi pada penelitian ini yaitu PTS Kopertis Wilayah IV, sedangkan sampel yang digunakan adalah proportional probability sampling, dimana ukuran sampelnya ditentukan dengan menggunakan pendekatan power analysispower test, sehingga diperoleh sampelnya berjumlah 157 PTS Kopertis Wilayah IV. Respondennya adalah pembantu dekan atau ketua jurusan dan pembantu rektor atau dekan. Pengumpulan data dilakukan dengan menggunakan teknik wawancara, observasi dan kuesioner yang telah diuji validitas dan reliabilitasnya. Alat uji analisis dengan menggunakan metode Structural Equation Model (SEM)-LISREL 8.3, dengan pendekatan second order.

\section{HASIL DAN PEMBAHASAN}

Berikut ini dipaparkan diagram jalur pengujian hipotesis pada gambar 1 . 


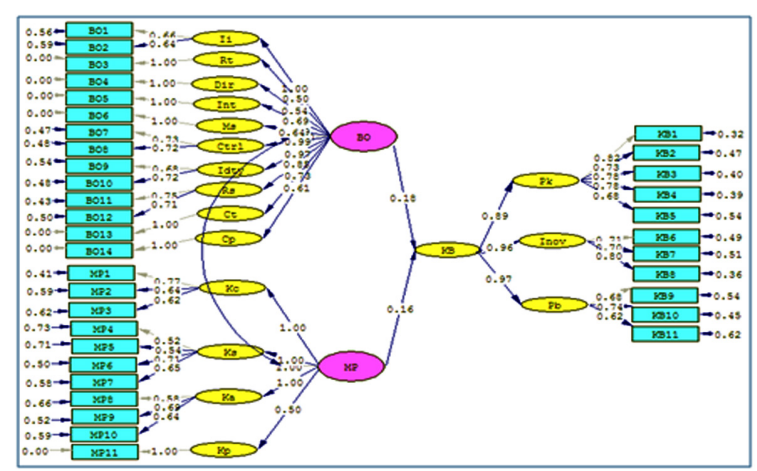

Gambar 1. Pengaruh Budaya Organisasi dan Manajemen Pengetahuan terhadap Keunggulan Bersaing

Dari hasil pengolahan data menggunakan software LISREL diperoleh hasil sebagai berikut :

Tabel 1. Persamaan Struktural Pengaruh Budaya Organisasi dan Manajemen Pengetahuan terhadap Keunggulan bersaing

\begin{tabular}{cccc}
\hline $\begin{array}{c}\text { Endegenous } \\
\text { Constructs }\end{array}$ & \multicolumn{3}{c}{$R^{2}$} \\
\hline \multirow{4}{*}{ Exogenous Constructs } & \\
KB & BO & MP & \\
& 0.18260 & 0.1564 & 0.094 \\
& $(1.7143)$ & $(1.3534)$ & \\
\hline
\end{tabular}

Sumber : Hasil Pengolahan Data : 2011

Keterangan: Angka dalam kurung adalah nilai statistik uji-t.

Setelah koefisien jalur dihitung, berikutnya, untuk membuktikan apakah budaya organisasi dan manajemen pengetahuan berpengaruh signifikan baik secara simultan maupun secara parsial terhadap keunggulan bersaing, maka dilakukan pengujian hipotesis. Pengujian hipotesis dimulai dari pengujian secara simultan dan dilanjutkan dengan pengujian secara parsial

Rumusan hipotesis statistik, untuk uji hipotesis secara simultan, adalah :

$\mathrm{H}_{0}: \gamma_{21}^{*}=\gamma_{22}^{*}=0$ Tidak ada pengaruh simultan dari Budaya Organisasi dan Manajemen Pengetahuan terhadap Keunggulan Bersaing

$\mathrm{H}_{1}: \gamma_{2 \mathrm{j}} \neq 0 ; \mathrm{j}=1,2 \mathrm{Ada}$ pengaruh simultan dari Budaya Organisasi dan Manajemen Pengetahuan terhadap Keunggulan Bersaing

Dari perhitungan nilai $\mathrm{R}^{2}$ sebesar 0.094 dengan banyak variabel eksogen untuk sub struktur pertama $(\mathrm{k}=2)$ dan $\mathrm{n}=157$ maka diperoleh nilai statistik uji $\mathrm{F}$ yaitu : $F=\frac{0.094 / 2}{(1-0.094) /(157-2-1)}=8.02$

Nilai F hitung adalah 8.02. Dari tabel F dengan tingkat signifikansi $5 \%$ dan derajat bebas pembilang $\mathrm{v}_{1}=2$, dan penyebut $\mathrm{v}_{2}=154$, diperoleh nilai $\mathrm{F}$ tabel adalah 3.055, selanjutnya dengan membandingkan kedua nilai ini diperoleh kesimpulan "Tolak Hipotesis Nol" yang artinya terdapat pengaruh simultan dari budaya organisasi dan manajemen pengetahuan terhadap keunggulan bersaing pada PTS Kopertis Wilayah IV. (kriteria penolakannya adalah tolak hipotesis nol jika nilai $\mathrm{F}$ hitung lebih besar dari nilai F tabel).

Berdasarkan analisis jalur dan uji hipotesis, dapat dinyatakan bahwa secara bersama-sama, bu- daya organisasi dan manajemen pengetahuan, mampu menjelaskan keragaman dari variabel keunggulan bersaing PTS Kopertis Wilayah IV sebesar $9,4 \%$, dapat diartikan bahwa budaya organisasi dan manajemen pengetahuan memberikan kontribusi secara bersama-sama sebesar 9,4\% terhadap keunggulan bersaing PTS Kopertis Wilayah IV, dengan kata lain hanya sebesar 9.4\% perubahan-perubahan yang terjadi pada keunggulan bersaing sebagai respon langsung dari adanya perubahan pada budaya organisasi dan manajemen pengetahuan.

Dalam hal individu PTS Kopertis Wilayah IV mempunyai inisiatif yang tinggi, dimana individu selalu berkreasi dan berinovasi tinggi, serta tetap bertanggung jawab, seperti PTS mengkreasi kurikulumnya dengan cara mengkreasi SAP-GBPP nya, secara bersamaan pula, PTS mengkreasi pengetahuan dengan cara membagikan kuesioner kepada pelanggan, melakukan benchmarking dan mendatangkan para ahli yang berkompeten di bidangnya, yang semuanya itu bertujuan untuk memperoleh pengetahuan, kemudian PTS pun menciptakan peraturan-peraturan baru untuk mendukung jalannya kurikulum yang dikreasi dan diinovasi tersebut, melakukan desain ulang materimateri pembelajarannya, serta aturan-aturan pendukungnya, semua hal tersebut dapat mengakibatkan PTS menciptakan inovasi di produknya, yaitu program studi yang unggul, seperti program dual degree, serta dapat pula menciptakan inovasi di proses, yaitu kurikulum yang baru dan berbeda (kurikulum yang unik) seperti kurikulum berbasis kompetensi (KBK), E-Learning, student centre learning $(S C L)$. Dalam hal PTS Kopertis Wilayah IV memberikan kompensasinya kepada pegawai dengan berdasarkan pada asas keadilan, dimana kompensasi diberikan berdasarkan pada nilai relatif setiap jabatan, sebanding dengan perguruan tinggi lainnya yang setara, kemudian kompensasi diberikan dengan berdasarkan pula pada asas kelayakan, yang sesuai dengan peraturanperaturan pemerintah dan sesuai dengan kemampuan PTS, secara bersamaan pula PTS pun memberikan pelatihan yang dijalankan dengan efektif, seperti pelatihan "service excellence" dan pelatihan "product knowledge", sehingga wawasan dan pengetahuan tentang pelayanan meningkat, wawasan dan pengetahuan tentang produk-produk perguruan tinggi juga meningkat, semua hal tersebut mengakibatkan pelayanan di PTS menjadi lebih berkualitas, dimana pegawai melakukan pelayanannya dengan lebih andal, lebih empati, lebih responsive (lebih cepat), lebih memuaskan dan sarana prasarana nya lebih memadai, selain itu PTS dapat menciptakan program studi yang unggul seperti program dual degree, kurikulum yang lebih unggul, seperti kurikulum berbasis kompetensi (KBK), student centre learning (SCL), E-Learning. Selanjutnya, dalam hal PTS melakukan pengendalian yang ketat, berupa peraturan dan pengawasan dari pimpinan, kemudian secara bersamaan, dilakukan pula penyimpanan pengetahuan dan aksesnya secara sistematis (hardcopy dan softcopy), hal tersebut mengakibatkan PTS dapat meminimalisasi biaya 
overhead, melakukan pengendalian program kerja menjadi lebih ketat, menjalankan lebih baik prinsip of scale nya, sehingga dapat tercapai biaya yang lebih rendah.

Sementara sisanya sebesar $90.6 \%$ mampu dijelaskan oleh faktor-faktor lain di luar kedua variabel eksogen yang diteliti. Faktor-faktor lain yang mempengaruhi keunggulan bersaing yaitu desain pekerjaan, yang terdiri dari identitas pekerjaan dan karir, kemudian staffing yang berupa rekruitmen, seleksi dan separation, serta pengukuran kinerja, pendidikan dan pelatihan, serta reward system, hal ini sesuai dengan yang dikemukakan oleh Jackson, Michael Hitt dan Angelo De Nisi (2003).

Setelah dijelaskan uji simultan, selanjutnya diuraikan uji parsialnya. Rumusan hipotesis statistik uji hipotesis parsial nya yaitu :

$\mathrm{H}_{0}: \gamma^{*}{ }_{21}=0$ Tidak terdapat pengaruh positif dari Budaya Organisasi terhadap Keunggulan bersaing

$\mathrm{H}_{1}: \gamma_{21}^{*}>0$ Terdapat pengaruh positif dari Budaya Organisasi terhadap Keunggulan Bersaing

$\mathrm{H}_{0}: \gamma_{22}^{*}=0$ Tidak terdapat pengaruh positif dari Manajemen Pengetahuan terhadap Keunggulan Bersaing

$\mathrm{H}_{1}: \gamma_{22}^{*}>0$ Terdapat pengaruh positif dari Manajemen Pengetahuan terhadap Keunggulan Bersaing

Hasil perhitungan statistik uji t student, memberikan nilai t-hitung budaya organisasi (1.71) lebih besar dibandingkan dengan nilai t-tabelnya (1.655), sedangkan nilai t-hitung manajemen pengetahuan (1.35), lebih kecil dibandingkan dengan nilai t-tabelnya (1.655), sehingga dapat disimpulkan bahwa untuk variabel budaya organisasi hipotesis nol ditolak sedangkan untuk variabel manajemen pengetahuan hipotesis nol diterima yang artinya terdapat pengaruh positif dari budaya organisasi terhadap keunggulan bersaing, sedangkan manajemen pengetahuan secara parsial tidak memberikan pengaruh positif terhadap keunggulan bersaing pada PTS Kopertis Wilayah IV. Berarti, segala bentuk peningkatan dari budaya organisasi, maka dapat memberikan peningkatan terhadap keunggulan bersaing pada PTS Kopertis Wilayah IV, sedangkan segala bentuk peningkatan dari manajemen pengetahuan, tidak memberikan peningkatan yang signifikan terhadap keunggulan bersaing pada PTS Kopertis Wilayah IV.

Koefisien jalur dari Budaya Organisasi terhadap Keunggulan bersaing menunjukkan nilai sebesar 0.1826 . Nilai ini merupakan besarnya efek langsung dalam satuan standar deviasi dari budaya organisasi terhadap keunggulan bersaing. Sehingga dapat dikatakan bahwa besarnya pengaruh langsung dari budaya organisasi terhadap keunggulan bersaing mencapai 0.1826 standar deviasi, yang berarti jika terjadi peningkatan satu standar deviasi dalam skala budaya organisasi, maka keunggulan bersaing akan meningkat sebesar 0.1826 standar deviasi dalam skala keunggulan bersaing.

Selanjutnya koefisien jalur dari manajemen pengetahuan terhadap keunggulan bersaing menunjukkan nilai sebesar 0.1564 . Nilai ini merupakan besarnya efek langsung dalam satuan standar deviasi dari manajemen pengetahuan terhadap keunggulan bersaing. Oleh karena itu, dapat dikatakan bahwa besarnya pengaruh langsung dari manajemen pengetahuan terhadap keunggulan bersaing mencapai 0.1564 standar deviasi, yang berarti jika terjadi peningkatan satu standar deviasi dalam skala manajemen pengetahuan, maka keunggulan bersaing akan meningkat sebesar 0.1564 standar deviasi dalam skala keunggulan bersaing.

Hal ini dapat diartikan bahwa jika PTS Kopertis Wilayah IV akan melakukan peningkatan terhadap keunggulanbersaingnya,makaharus lebihmemperhatikan pada penciptaan budaya organisasi menjadi lebih kuat. Dalam hal anggota organisasi PTS Kopertis Wilayah IV meningkatkan inisiatifnya dengan berpikir lebih kreatif, serta adanya peningkatan pengarahan yang lebih jelas dari pimpinan PTS, maka dapat meningkatkan inovasi di produk PTS seperti program studi unggulan, kurikulum, metode PBM seperti kurikulum berbasis kompetensi (KBK), E-Learning, berakibat pula penetapan strategi biaya menjadi lebih rendah. Selanjutnya, dengan adanya peningkatan sistem pemberian kompensasi yang lebih adil dan lebih layak pada PTS Kopertis Wilayah IV, maka mengakibatkan peningkatan pada pelayanan menjadi lebih cepat, lebih akurat, lebih memuaskan, lebih cepat tanggap, lebih andal, lebih empati dan sarana prasarana nya menjadi lebih memadai. Begitu pula dengan adanya peningkatan pengendalian yang lebih ketat, yang berupa adanya peraturan dan adanya peningkatan pengawasan dari pimpinan, berdampak pada peningkatan efisiensi dan tercapainya biaya yang lebih rendah.

Selanjutnya, dapat dijelaskan bahwa, dalam hal PTS Kopertis Wilayah IV melakukan peningkatan pertemuan formal, seperti pelatihan "customer sevice" dan pelatihan "product knowledge" yang efektif, maka tidak memberikan peningkatan yang berarti terhadap kualitas pelayanan menjadi lebih cepat, lebih akurat, lebih memuaskan, lebih tanggap, lebih empati, begitu pula tidak memberikan peningkatan yang nyata terhadap inovasi di program studi, kurikulum, dan metode PBM. Selanjutnya, dalam hal PTS melakukan penyimpanan yang lebih sistematis baik hardcopy dan softcopy, serta lebih meningkatkan sistem kemudahan akses data, tidak memberikan peningkatan yang nyata terhadap pelayanan menjadi lebih berkualitas, dimana pelayanan menjadi lebih cepat, lebih memuaskan, lebih tanggap, lebih empati, begitu pula tidak mengakibatkan menjadi lebih inovatif di program studi, kurikulum dan metode PBM nya, serta tidak mengakibatkan peningkatan efisiensi atau penetapan biaya menjadi lebih rendah.

Hal ini dapat diartikan pula bahwa dalam hal PTS Kopertis Wilayah IV melakukan peningkatan manajemen pengetahuan menjadi lebih efektif, maka harus dilakukan bersama-sama dengan penciptaan budaya organisasinya yang lebih kuat agar dapat memberikan peningkatan keunggulan bersaingnya.

\section{SIMPULAN}

Dari penjelasan yang telah diuraikan sebelumnya dapat disimpulkan bahwa budaya organisasi dan manajemen pengetahuan secara bersama-sama 
berpengaruh secara signifikan terhadap keunggulan bersaing pada PTS Kopertis Wilayah IV, artinya perubahan-perubahan yang terjadi pada keunggulan bersaing PTS Kopertis Wilayah IV, merupakan akibat/ respon dari adanya perubahan-perubahan pada budaya organisasi dan manajemen pengetahuan secara bersamasama. Berarti pula bahwa dalam hal PTS Kopertis Wilayah IV melakukan penciptaan budaya organisasi menjadi lebih kuat, maka harus dilakukan bersama-sama dengan peningkatan mana-jemen pengetahuan menjadi lebih efektif, agar dapat memberikan peningkatan keunggulan bersaingnya, begitu pula sebaliknya.

Secara masing-masing, budaya organisasi mempunyai pengaruh positif terhadap keunggulan bersaing, yang berarti penciptaan budaya organisasi menjadi lebih kuat dapat meningkatkan keunggulan bersaing pada PTS Kopertis Wilayah IV. Sedangkan manajemen pengetahuan tidak mempunyai pengaruh positif terhadap keunggulan bersaing, yang berarti peningkatan efektivitas manajemen pengetahuan tidak mengakibatkan peningkatan keunggulan bersaing pada PTS Kopertis Wilayah IV.

\section{DAFTAR PUSTAKA}

Aulawi, Hilmi. 2009. Pengembangan Infrastruktur Knowledge Untuk Meningkatkan Innovation Capability. Pascasarjana Institut Teknologi Bandung

Akhmadi, Hari. 2008. 800 PTS Gulung Tikar. Kompas:http://www.kompas.com/read/ xml/2008/08/01/10552722/800.pts.gulung.tikar

Bateman, Thomas S. \& Shell, Scott A. 2007. Management: Leading and Collaborating in a Competitive World, 7ed. Ch.1

Birkinsaw, J. \& Sheehan, T. 2002. Managing The Knowledge Life Cycle. Sloan Management Review, 44(1), 75-84

Cascio, Wayne F. 2003. Managing Human Resources: Productivity, Quality of Work Life, Profits, 6th Edition, The McGraw-Hill

Dalkir, K. 2005. Knowledge Management in Theory and Practice, United Kingdom, Elsevier Butterworth-Heinemann

Dessler, Gary. 2007. Human Resource Management, Prentice-Hall, Inc. Upper Saddle River, New Jersey

Hsu, Hsiu Yueh. 2006. Knowledge Management and Intellectual Capital, A Dissertation Submitted in Partial Fulfilment of the Requirement for the Doctoral og Philosophy, UMI Microform 321502

Indiyati, Dian. 2012. The Influence of Organizational Culture and Knowledge Management on the Intellectual Capital and its Impacts on Competitive Advantage, Dissertation.

Jackson, Susan E, Michael A. Hitt, Angelo S. Denisi. 2003. Managing Resources for Knowledge-Based Competition; Managing Knowledge for Sustained Competitive Advantage
Kotler, P. 2010. Marketing Management, The Mollenium Edition, Prentice Haal International, Unc., Upper Saddle River, New Jersey

Kreitner and Angelo Kinicki. 2008. Organizational Behavior. Mc. Graw Hill

Levitt, Steven D. 1997. Organizational Learning. Annual Review Sociology, 14:319-340

Liao, S.H., Fei, W.C. \& Chen, C.C. 2007. Knowledge Sharing, Absorptive Capacity and Innovation Capability; An Empirical Study of Taiwans Knowledge-Intensive Industries, Journal of Information Science, Vol. 20, No. 10, 1-20

Moharman, Susan A. 2003. Designing Work for Knowledge-Based Competition, Managing Knowledge for Sustained Competitive Advantage. Published by Jossey-Bass A Wiley Imprint, San Francisco, CA

Mondy, Wayne R. \& Noe, Robert, M. 2006. Human Resource Management. New Jersey. Pearson Education

Nguyen, Que Thi Nguyet, Philip A Neck, Thanh Hai Nguyen. 2009. The Critical Role of Knowledge Management in Achieving and Sustaining Organisational Competitive Advantage; International Business Research

Noe, Raymond A, John R. Hollenbeck, Barry Gerhart \& Patrck M. Wright. 2010. Human Resources Management: Gaining a Competitive Advantage, $4^{\text {th }}$ edition, McGraw-Hill/Irwin, New York

Noe, Raymond A, Jason A. Colquitt, Marcia J. Simmering, \& Sharon A. Alvarez. 2003. Knowledge Management Developing Intellectual and Social Capital; Managing Knowledge for Sustained Competitive Advantage

Nonaka, Ikujiro \& Hirotaka Takeuchi. 1995. The Knowledge Creating Company, New York Oxford University, Inc.

Nonaka, Ikujiro \& Konno, N. 2007. The Concept of Ba: Building a Foundation for Knowledge Creation. California Management Review, Vol. 40, No. 3, 40-54

Rivai, Veithzal. 2004. Manajemen Sumberdaya Manusia Untuk Perusahaan. Jakarta: Grafindo

Robbins, Stephen P. 2008. Organizational Behavior • Prentice Hall, Inc. New Jersey

Ruky, Ahmad. 2002. Sistem Pengupahan. PT Gramedia Pustaka Utama,. Jakarta

Schuler, Randall., S. \& Susan E. Jacson. 2006. Linking Competitive Strategies with Human Resource Management Practice, The Academy of Management, Vol. 1, No. 3, hal. 207-219

Setiawan, WawanLulus.2010.KendalaMengembangkan Institusi PTS, http://s3komunikasiunpad.multiply. com/journal 
Sopiah. 2008. Perilaku Organisasional. Penerbit Andi. Thoha, Miftah. Yogyakarta

Syaiful. 2007. Analisis Faktor-Faktor Utama Yang Mempengaruhi Keinginan Untuk Sharing Pengetahuan (Studi Kasus: PT. Telekomunikasi Indonesia, TBK), Institut Teknologi Bandung

Tan, Victor S.L. 2002. Changing Your Corporate Culture. Singapore: Times Books International

Want, Jerome. 2006. Corporate Culture, New York, St. Martin's Press
Werther, William B \& Keith Davis. 1996. Human Resources and Personnel Management, Mc Graw Hill Boston

Widayana, Lendy. 2005. Knowledge Management: Meningkatkan Daya Saing Bisnis, Cetakan Pertama, Bayumedia Publishing, Malang

Zimmerer, W. Thomas, Norman M. Scarborough. 1996. Entreupreneurship and The New Venure

Zhou, Albert Z \& Dieter Fink. 2003. The Intellectual Capital Web A Systematic Linking of Intellectual Capital and Knowledge Management: Journal of Intellectual Capital 